\title{
Neonatal group A streptococcal meningitis: a case report and review of the literature
}

\author{
Amer A Lardhi
}

Address: Department of Pediatrics, King Fahd Hospital of the University, Alkhobar, Saudi Arabia

Email: Amer A Lardhi - drlardhi@hotmail.com

Published: 18 August 2008

Cases Journal 2008, I:108 doi:10.1186/1757-1626-1-108

This article is available from: http://www.casesjournal.com/content/I/I/I08

(c) 2008 Lardhi; licensee BioMed Central Ltd.

This is an Open Access article distributed under the terms of the Creative Commons Attribution License (http://creativecommons.org/licenses/by/2.0), which permits unrestricted use, distribution, and reproduction in any medium, provided the original work is properly cited.
Received: II July 2008
Accepted: 18 August 2008

\begin{abstract}
Introduction: Group A streptococcus is a rare cause of neonatal meningitis. A review of MEDLINE database since 1966 revealed only 15 documented cases of group A streptococcal meningitis in neonates.

Case report: A previously healthy 28 days old male neonate presented with a history of irritability, fever, and focal seizures. Cerebrospinal fluid analysis and culture confirmed the diagnosis of group A streptococcal meningitis. The clinical course was complicated by the development of brain abscess. The patient made full recovery following a surgical drainage of the abscess and a 6 week total course of antibiotics.

Conclusion: Although it is an uncommon organism, clinician should always consider group $A$ streptococcal infection and its potential complications in the differential diagnosis and management of neonatal meningitis.
\end{abstract}

\section{Background}

Since the introduction of antibiotics, group A streptococcal infection has been an uncommon disease in neonates. Thirty-nine patients with severe neonatal disease caused by group A streptococcus (GAS) have been described since 1966 [1]. Meningitis caused by GAS is reported in only 15 neonates during same period [2-13]. This case report describes a neonate with GAS meningitis seen at a university hospital and provides an overview of well-documented cases in the English-language literature over past 40 years.

\section{Case report}

A 28 days old boy was presented to the Emergency Department with a history of fever, irritability, poor feeding of 1 week duration and right-sided focal seizures on the day of presentation. He was born after an uncomplicated pregnancy and delivery. An elder brother had developed symptomatic pharyngitis with fever, sore and congested throat 10 days prior to the neonate's disease. This pharyngitis, however, was not microbiologically investigated. He was recovered after a one week course of antibiotic. Upon examination, the patient looked ill, and irritable. Vital signs were stable. Anterior fontanel was normal and there was no neurological deficit. The peripheral blood white cells (WBC) were $33,600 / \mathrm{mm}^{3}$ with differential count $61 \%$ Neutrophils, $18 \%$ Lymphocytes, $6 \%$ Monocytes and $10 \%$ Eosinophils. C-reactive protein was positive. Cerebrospinal fluid (CSF) was turbid and showed 23,520 $\mathrm{WBC} / \mathrm{mm}^{3}$ with $82 \%$ Neutrophils, $18 \%$ Lymphocytes and 3 red blood cells $/ \mathrm{mm}^{3}$. CSF protein was $502 \mathrm{mg} / \mathrm{dl}$, Glucose $5 \mathrm{mg} / \mathrm{dl}$ (simultaneous blood glucose $98 \mathrm{mg} / \mathrm{dl}$ ). Latex antigen test was negative for Hemophillus influenzae B, Neisseria meningitides, Escherichia Coli, Streptococcus group B and Streptococcus pneumoniae. Gram positive cocci were seen in the deposit. He was treated 
with intravenous cefriaxone and vancomycin. The CSF culture yielded group A beta hemolytic Streptococci. Subtyping of the organism was not available. Vancomycin was discontinued after results of culture. Given the history of focal seizures, head MRI, performed on the seventh hospital day, and showed a large lobulated abscess in the left parieto-occipital region [Figure 1]. The patient underwent drainage of the abscess. No organisms grew in the culture of the pus (presumably owing to the preceding antibiotic treatment). The child was discharged after 6 weeks of treatment. At the age of 13 month, hearing test and neurological examination were normal.

\section{Discussion}

In the pre-antibiotic era, GAS was a major cause of neonatal sepsis and puerperal infections. Meningitis accounted for $10-20 \%$ of these infections with fatality rate of $95 \%$. Since the advent of antimicrobial therapy, meningitis caused by GAS is rarely reported in adults or children, with less than $1 \%$ of all cases of bacterial meningitis [6].

Since the1980's an increase in the incidence of invasive infections caused by GAS has been noted. A review of GAS meningitis in children beyond the neonatal period describes only 31 well-documented patients in world literature in the past 30 years [14].

The present case included a MEDLINE search of the English literature from 1966 revealed only 16 neonates with GAS meningitis [Table 1]. All but two patients in the current review developed late onset ( $>7$ days of age) neonatal meningitis. Associated conditions included sepsis, erysipelas, necrotizing fasciitis, necrotizing enterocolitis,

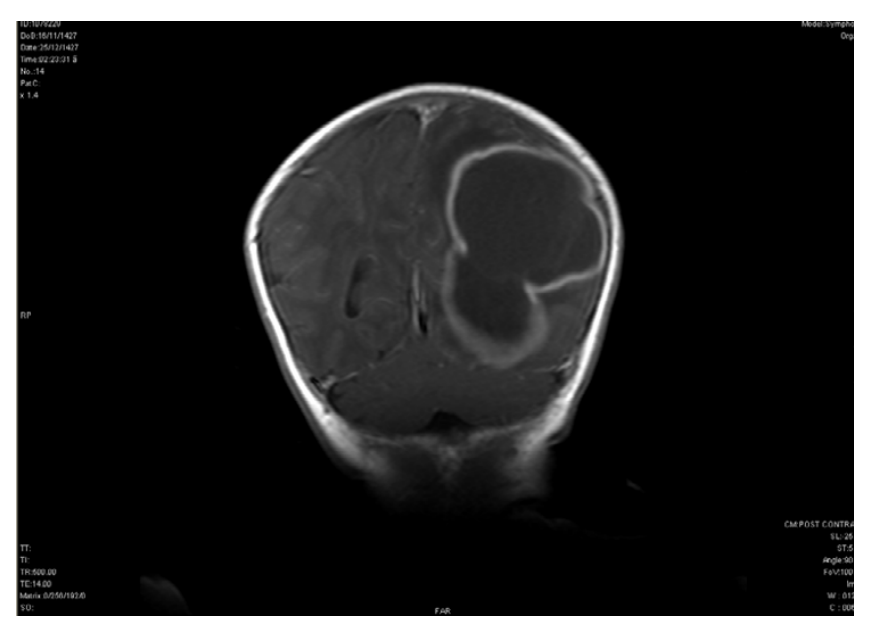

Figure I

Coronal section of brain MRI with contrast showing a large lobulated collection in the parieto-occipital region. cellulitis, and respiratory infection. No associated or preceding illness was reported in $6(40 \%)$ patients.

A 2004 review of GAS invasive infection in the neonates has described 39 patients since 1966 in the world literature [1]. Vertical transmission accounted for the majority of invasive early onset GAS disease in these neonates. Sixty percent of the mothers who delivered infants with early onset of GAS disease developed puerperal sepsis, toxic shock-like syndrome or both in the peripartum period. The mode of transmission in the majority of invasive late onset cases is unknown. Vertical transmission or postnatal acquisition of focal GAS infection such as pharyngitis and episiotomy abscess is a probable source of transmission. There was no a recognizable underlying illness or predisposing factor of GAS meningitis in the present case. However, a family member had developed symptomatic pharyngitis 10 days prior to the onset of the disease, which may have been the source of infection.

GAS is sensitive to a variety of antibiotics administered either alone or in combination. Penicillin was the most commonly prescribed antibiotic for GAS invasive infection in children $[14,15]$. Burnett et al in his case series reported a favorable outcome when combind clindamycin with beta lactam penicillin [15]. In neonates with GAS meningitis penicillin was used in $(77 \%)$. Other antibiotics used included amino glycosides, second and third generation cephalosporin, and vancomycin [table 1].

The choice of empiric antibiotic treatment for neonates with meningitis usually involves ampicillin and gentamicin, or ampicillin and cefotaxime.

The clinical course of GAS neonatal meningitis was associated with major complications including seizures in 8 patients $(60 \%)$ disseminated intravascular coagulopathy (DIC), cardio respiratory insufficiency, hepatitis, and Waterhouse-Frederichsen syndrome. Brain abscess developed in 3 patients [table 1].

Group A streptococcus is an uncommon cause of brain abscess in children and adults. Etiology of brain abscess in the reported cases includes meningitis, contiguous spread from a middle ear infection, facial furuncles and hematogenous spread from distant site.

In neonates brain abscesses are very rare. It is usually occurs as complications of bacterial meningitis or bacteremia. Maternal factors include mastitis and genitourinary tract infection can be an important source of neonatal brain abscesses. They are most often caused by gram negative organisms. The abscesses are often large and may be multiple. Symptoms of seizures, signs of sepsis and bulg- 
Table I: Group A streptococcal meningitis in neonates.

\begin{tabular}{|c|c|c|c|c|c|c|}
\hline Case No. & Age/Sex & $\begin{array}{l}\text { Associated } \\
\text { Condition }\end{array}$ & Complication & Management & $\begin{array}{l}\text { Outcomel } \\
\text { Sequelae }\end{array}$ & Reference \\
\hline I & 6 days $/ M$ & Erysipelas & None & Penicillin + Kanamycin & Recovered/NA* & 2 \\
\hline 2 & I Mo./F & None & Seizures & NA & Died & 3 \\
\hline 3 & 8 days $/ M$ & None & Seizures & NA & Died & 3 \\
\hline 4 & 17 days/F & Umbilical sepsis & None & Penicillin & Recovered/NA & 4 \\
\hline 5 & 3 days $/ F$ & $\begin{array}{l}\text { Necrotizing fasciitis, } \\
\text { septicemia }\end{array}$ & None & Penicillin & Recovered & 5 \\
\hline 6 & I 4 days/F & Erysipelas & Seizures, D.I.C*. & Penicillin & Recovered & 6 \\
\hline 7 & 14 days/NA & None & None & Cefotaxime + Ampicillin & Recovered & 7 \\
\hline 8 & 26 days $/ M$ & $\begin{array}{l}\text { Paronychiae, } \\
\text { porencephalic cyst }\end{array}$ & Seizures & $\begin{array}{l}\text { Penicillin + Cefuroxime+ } \\
\text { Gentamycine }\end{array}$ & $\begin{array}{l}\text { Recovered/ } \\
\text { Hydrocephalus }\end{array}$ & 8 \\
\hline 9 & 13 days/F & Cellulitis of both feet & Seizures, Hepatitis & Penicillin + Cefuroxime & Died & 8 \\
\hline 10 & I Mo./F & None & $\begin{array}{l}\text { Multiple brain abscess, } \\
\text { seizures }\end{array}$ & Penicillin & Recovered/NA & 9 \\
\hline II & I Mo./F & Sepsis + RSV* Infection & $\begin{array}{l}\text { Sepsis, Waterhouse- } \\
\text { Friderichsen syndrome }\end{array}$ & NA & Died & 10 \\
\hline 12 & 33 days $/ F$ & Pneumonia & NA & Penicillin + Gentamycin & Died & 11 \\
\hline 13 & 34 days/NA & None & NA & Penicillin + Gentamycin & Recovered/NA & 11 \\
\hline 14 & I Mo./NA & NEC*+ Septicemia & NA & Penicillin + Gentamycin & Died & 12 \\
\hline 15 & 24 days $/ F$ & None & $\begin{array}{l}\text { Seizures, brain abscess, } \\
\text { cardiorespiratory } \\
\text { Insufficiency }\end{array}$ & NA & Died & 13 \\
\hline 16 & 28 days $/ M$ & None & Seizures, brain abscess & $\begin{array}{l}\text { Ceftriaxone }+ \\
\text { Vancomycin }\end{array}$ & Recovered & This case \\
\hline
\end{tabular}

*D.I.C-Disseminated intravascular coagulation, NA-Data not available, NEC-Necrotizing entercolitis RSV-Respiratory syncetial virus

ing fontanels are frequently seen in neonatal brain abscesses.

Eight (50\%) patients with neonatal GAS meningitis died. This is higher than the mortality rate reported in neonates with meningitis caused by several other types of pathogens, and the mortality rate of GAS meningitis reported in children beyond the neonatal period [14]. No neurological sequelae were reported in 4 patients on whom follow up data is available.

\section{Conclusion}

GAS meningitis remains an uncommon but serious disease affecting mostly older neonates. Parent and siblings of the patients constitute the source of infection and may unknowingly infect the neonates. Since invasive infection is on the increase, clinicians should always consider GAS in the differential diagnosis of neonatal sepsis and meningitis. Prompt and appropriate treatment may reduce complications and mortality.

\section{Consent}

Written informed consent was obtained from the patient's parent for publication of this case report and accompanying image. A copy of the written consent is available for review by the Editor-in Chief of this journal.

\section{Competing interests}

The author declares that they have no competing interests.

\section{References}

I. Miyairi I, Berlingieri D, Protic J, Belko J: Neonatal invasive group A Streptococcal disease: case report and review of the literature. Pediatr Infect Dis J 2004, 23: I6I-5. Review

2. Dillon HC: Group A type 12 Streptococcal infection in a newborn nursery. Successfully treated neonatal meningitis. Am J Dis Child 1966, I I 2: I77-84.

3. Ramanathan K, Grossman A: Neonatal Streptococcal meningitis. III Med J 1967, I32:705-7.

4. Nelson JD, Dillon HC, How JB: A prolonged nursery epidemic associated with a newly recognized type of group A Streptococcus. J Pediatr 1976, 89:792-6.

5. Nutman J, Heing E, Wilunsky E, Reisner SH: Acute necrotizing fasciitis due to Streptococcal infection in a newborn infant. Arch Dis Child 1979, 54:637-9.

6. Murphy DJ: Group A Streptococcal meningitis. Pediatrics 1983 , 7l:l-5.

7. Baumgartner ET, Augustine RA, Steele RW: Bacterial meningitis in older neonates. Am J Dis Child 1983, 137:1052-4.

8. Coulter JB, Buchannon CR, Vellodi A, Hart CA, Sills JA: Group A Streptococcal infection in the newborn. Lancet 1984, 2:355-6.

9. Wong VK, Wright HT: Group A beta-hemolytic streptococci as a cause of bacteremia in children. Am J Dis Child 1988, | 42:83|-3.

10. Givner LB: Invasive disease due to Group A beta-hemolytic Streptococci: continued occurrence in children in North Carolina. South Med J 1998, 91:333-7.

II. Mullholand EK, Ogunlesi OO, Adegbola RA, Weber M, Sam BE, Palmer A, Manary MJ, Secka O, Aidoo M, Hazlett D, Whittle H, Greenwood BM: Etiology of serious infections in young Gambian infants. Pediatr Infect Dis J 1999, 18:S35-4I.

12. Muhe L, Tilahum M, Lulseged S, Kebede S, Enaro D, Ringertz S, Kronvall G, Gove S, Mullholand EK: Etiology of pneumonia, sepsis, and meningitis in infants younger than three months of age in Ethiopia. Pediatr Infect Dis J 1999, I8:S56-6I.

13. Verboon-Maciolek MA, Krediet TG, van Erthbruggen I, Gerards LJ, Fleer A: Severe neonatal group A Streptococcal disease. Eur J Pediatr 2000, I 59:450-2. 
14. Shetty AK, Frankel LR, Maldonado Y, Falco DA, Lewis DB: Group A Streptococcal meningitis: Report of a case and review of literature since 1976. Pediatr Emerg Care 200I, 17:430-4.

15. Burnett AM, Domachowske JB: Therapeutic considerations for children with invasive group A streptococcal infection: A case series report and review of the literature. Clinc Pediatr 2007, 46:550-5.

Publish with Bio Med Central and every scientist can read your work free of charge

"BioMed Central will be the most significant development for disseminating the results of biomedical research in our lifetime. " Sir Paul Nurse, Cancer Research UK

Your research papers will be:

- available free of charge to the entire biomedical community

- peer reviewed and published immediately upon acceptance

- cited in PubMed and archived on PubMed Central

- yours - you keep the copyright

Submit your manuscript here:

http://www.biomedcentral.com/info/publishing_adv.asp 